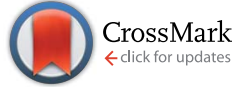

Cite this: J. Anal. At. Spectrom., 2016, 31,2031

\title{
Effects of easily ionisable elements on copper and zinc lines excited in a plasma pencil
}

\author{
Magda Dvořáková, ${ }^{a}$ Aleš Hrdlička, ${ }^{\text {ab }}$ Pavel Slavíček, ${ }^{c}$ Viktor Kanickýab \\ and Vítězslav Otruba ${ }^{a}$
}

The influence of Easily Ionizable Elements (EIE) (chlorides of $\mathrm{Na}, \mathrm{K}, \mathrm{Mg}, \mathrm{Ca}$, Sr and $\mathrm{Ba}$ ) on the measured spectral lines intensities of copper and zinc excited in a capacitively coupled tubular discharge, known as a plasma pencil, is described. A strong decrease was observed in the dependence on the concentration of the EIE. The decrease is not linear. Addition of $\mathrm{NaCl}, \mathrm{KCl}$ or $\mathrm{BaCl}_{2}$ causes a steep decrease of the copper or zinc signal for a relatively narrow range of $0.05-0.80 \mathrm{~g} \mathrm{I}^{-1}$. Other EIE, with relatively higher ionization energies, even caused an increase of the $\mathrm{Cu}$ I 324.754, 327.396, 510.554 and $578.213 \mathrm{~nm}$ and Zn I 213.856, 468.014, 472.216 and 481.053 nm signals. Higher EIE concentrations, up to $4 \mathrm{~g} \mathrm{l}^{-1}$, bring only moderate signal suppression or even a weak signal increase. Atoms of $\mathrm{Mg}$, $\mathrm{Ca}$ and $\mathrm{Sr}$ likely undergo preferential partial ionization but less than $\mathrm{Na}, \mathrm{K}$ and $\mathrm{Ba}$ so that $\mathrm{Cu}$ and $\mathrm{Zn}$ atoms do not have enough energy for their ionization but still have enough energy for excitation. More $\mathrm{Cu}$ and $\mathrm{Zn}$ excited atoms, instead of ions, are then available and stronger $\mathrm{Cu}$ and $\mathrm{Zn}$ atomic emission is measured. Atoms of $\mathrm{Na}, \mathrm{K}$ and $\mathrm{Ba}$ are so much ionized that $\mathrm{Cu}$ and $\mathrm{Zn}$ atoms even loose energy for their excitation. A stronger decrease was found for the copper line than for the zinc line. An explanation can be done through inelastic collisions between $\mathrm{Cu}$ and the EIE excited atoms with very similar energetic levels. The influence of the EIE on the plasma properties was also monitored by calculation of excitation (2900 \pm $280) \mathrm{K}$, rotational temperatures $(1000 \pm 160) \mathrm{K}$ and electron number density of $(4.6 \pm 0.7) \times 10^{19} \mathrm{~m}^{-3}$; but no significant change was observable.

Received 14th June 2016 Accepted 29th July 2016 DOI: $10.1039 / c 6 j a 00215 c$ www.rsc.org/jaas

\section{Introduction}

Plasma pencil is a capacitively coupled plasma (CCP) radiofrequency jet discharge, operated typically in argon, at atmospheric pressure. ${ }^{1}$ It had been originally designed and used for surface treatment of both recent and ancient objects. ${ }^{2,3}$ The convenience for special polymer film deposition has also been proven. ${ }^{4}$ It has been further tested as an alternative excitation source for elemental analysis of liquids. ${ }^{5}$ The analytical profit of the plasma pencil has been shown during the determination of $\mathrm{Li}, \mathrm{Na}, \mathrm{Mg}, \mathrm{Ca}, \mathrm{Cu}$ and $\mathrm{Zn}$ in aqueous solutions as representatives of alkali, alkali-earth and transition metals. ${ }^{5,6}$

Real time analyses are more complicated in the presence of (i) acids, (ii) organics, (iii) easily ionisable elements (EIE) and (iv) other substances in the sample matrix, even if a very robust

\footnotetext{
${ }^{a}$ Masaryk University, Faculty of Science, Department of Chemistry, Kamenice 753/5, 62500 Brno, Czech Republic. E-mail: mdvorakova38@gmail.com; viktork@chemi. muni.cz; Fax: +420 54949 2443; Tel: +420 549494774

${ }^{b}$ Central European Institute of Technology, Masaryk University (CEITEC MU), Kamenice 753/5, 62500 Brno, Czech Republic. E-mail: ahrdlicka@chemi.muni.cz; ales2003h@centrum.cz; Fax: +420 54949 2443; Tel: +420 549493518

'Masaryk University, Faculty of Science, Department of Physical Electronics, Kotlárská 267/2, 61137 Brno, Czech Republic. E-mail: ps94@sci.muni.cz; Fax: +420 54121 1214; Tel: +420 549496830
}

inductively coupled plasma optical emission or mass spectrometry (ICP-OES/MS) is used. ${ }^{7-16}$ The presence of acids modifies the aerosol particle distribution and depresses the nebulisation efficiency due to the enhanced viscosity, particle evaporation, analyte atomization and analyte excitation. ${ }^{8,11,13}$ Greater suppression effects were observed for an ultrasonic nebulizer than for a Meinhard pneumatic nebulizer in the presence of nitric or hydrochloric acid. ${ }^{13}$ Any discharge-based excitation source may also suffer from some matrix interferences originating in the plasma processes. ${ }^{7-24}$ Especially EIE from the groups of alkali and alkali earth metals can be a major source of these effects. ${ }^{8-26}$ These elements shift the ionisation equilibrium of the analytes towards atoms due to their excessive

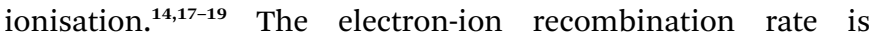
increased and ionic lines might be suppressed as a consequence. ${ }^{14}$ The lower the ionization potential of the interferents, the higher the matrix effect is pronounced. ${ }^{14}$ Substantial EIE suppression effects were also proved for laser ablation (LA)-ICP$\mathrm{MS}$, e.g. with Rb introduced into the ICP after de-solvation of the original $\mathrm{Rb}$ single element solution to exclude the influence of water. ${ }^{15}$ Practical experience shows a relatively low limit of about $1.5 \mathrm{mg} \mathrm{l}^{-1}$ for $\mathrm{Pb}$ isotope ratio measurements with ICPmulticollector MS, which is the most accuracy-demanding issue, together with other isotope ratio measurements. ${ }^{16}$ The 
EIE effect is always present; ${ }^{\mathbf{8 - 1 6}}$ but for ICP discharges it can be minimized by careful selection of robust operating conditions. ${ }^{8-16}$ The measured magnitude of the matrix interference also depends on the observation point with respect to the discharge topography, on gas flow rates, sample uptake and nebulization system. ${ }^{\mathbf{1 2}}$ The effect was confirmed for alkaline metals and alkaline earth metals. ${ }^{9}$ Partial effects of single elements cannot be summed to get the total effect, which is mostly lower but sometimes higher than the sum of the contributions of the single elements in ICP. ${ }^{9}$ The compensation for this effect can be done not only by addition of a standard, but also by normalization to the most convenient internal standard element for a radial observation mode. ${ }^{10}$ It was further shown that the internal standard emission line should be selected experimentally and that the axial observation mode should not be used in this case. ${ }^{\mathbf{1 0}}$

The effect of EIE is more pronounced in less powered excitation sources such as CCP, ${ }^{17-21}$ microwave induced plasma $(\mathrm{MIP})^{22,23}$ and glow discharges. ${ }^{24}$ In addition to the alkali metals, ${ }^{25,26} \mathrm{Ca}$ was found to affect CCP. ${ }^{17}$ In general, the EIE effect on analyte line intensities is not unambiguous ${ }^{18,19}$ and both signal ${ }^{\mathbf{1 9 , 2 5 , 2 6}}$ and limit of detection (LOD) ${ }^{\mathbf{1 8 , 2 5 , 2 6}}$ enhancement, and suppression, are observed. The effect in CCP depends on the selected analytical line, but $\mathrm{Mg}$ and $\mathrm{Ca}$ increase the intensity while $\mathrm{Na}$ and $\mathrm{K}$ have mostly depressive effects. ${ }^{26}$ The intensity trends also may not be monotonous, which is nicely shown in supplement 4 of ref. 26 .

The results of these studies suggest two opposing mechanisms for interference from EIE in the CCP source, one causing an enhancement of analyte signal and the other causing a depression. It was reported that a certain amount of EIE causes an enhancement of the analyte signal and outweighs the factors acting to suppress the signal. The explanation may lie in the fact that EIE are introduced as dissolved chlorides or nitrates. Plasma induced dissociation of volatile chloride compounds, an equilibrium shift toward atoms, and enhanced electron impact excitation due to an alteration of both the electron density and energy distribution, are the most probable reasons for the enhancement of analyte signal in the presence of smaller amounts of matrix species. The supposed suppression mechanisms are plasma induced dissociation of matrix molecules and collisional ionization of the matrix element. These mechanisms cause an enhanced consumption of energetic electrons in the plasma. Next, ionization of the EIE produces a lot of low energy electrons in the plasma. ${ }^{19}$ An energy radiative loss mechanism based on the strong sodium-atom radiation has been proposed. ${ }^{19}$ Also, changes in the shape of the CCP torches and different analyte distributions along the discharge axis were observed under the presence of EIE. ${ }^{\mathbf{1 8 , 2 0}}$

It was reported above that the EIE induced matrix effects are very complex, and due to the differences in the constructions of the CCP torches and forwarded power, plasma gas, sampling gas and observation position, their knowledge cannot be simply applicable to our CCP plasma pencil. A universal theory for much more widespread ICP has not been created. ${ }^{15}$ Any construction change can induce substantial changes in the EIE action.
Our study is aimed to show the EIE effect on the emission of $\mathrm{Cu} \mathrm{I}$ and $\mathrm{Zn} \mathrm{I}$ lines. Representative EIE were: $\mathrm{Na}$ and $\mathrm{K}$ from the first group as the most frequent alkali metals present in salted solutions and $\mathrm{Mg}, \mathrm{Ca}, \mathrm{Sr}$ and $\mathrm{Ba}$ from the second group. Copper and zinc were chosen as representatives of relatively less ionizable and excitable elements because their emission in the plasma pencil can be easily detected.,

\section{Experimental}

The experimental arrangement was the same as in our previous work. ${ }^{\mathbf{5}, \mathbf{6}}$ The scheme is depicted in Fig. 1 . The facility consisted of a Cesar $136 \mathrm{RF}$ generator $13.56 \mathrm{MHz}$ (Advanced Energy, China), a laboratory made impedance matching unit with two electrode-holders with holes containing a horizontally threaded quartz tube (o.d. $4 \mathrm{~mm}$, i.d. $2 \mathrm{~mm}$ ) with a fused T-piece for aerosol inflow. The sample introduction system employed a Scott spray chamber with a pneumatic concentric nebulizer, a peristaltic pump (Gilson, USA) delivering $0.7 \mathrm{ml} \mathrm{min}^{-1}$ of the test solution and Tygon tubing. The plasma gas was controlled with a mass flow controller (Omega, USA) and maintained at a flow rate of $41 \mathrm{~min}^{-1}$. The carrier gas streaming through the nebulizer was controlled with a mechanical rotameter and maintained at $0.251 \mathrm{~min}^{-1}$. The initial carrier gas pressure was 3 bar. The purity of the argon used was 4.6. The spectra acquisition was done with rail movable collection optics connected through an optical fibre to a monochromator (Jobin Yvon Horiba FHR 1000, grating 2400 groves per mm) equipped with a Symphony CCD camera cooled by a four stages Peltier cooler. The integration time for copper was $0.5 \mathrm{~s}$ at the slit width of $50 \mu \mathrm{m}$ and for zinc, $5 \mathrm{~s}$ at $100 \mu \mathrm{m}$.

\section{Test solutions}

All the solutions were prepared from deionized water and stock single element (Cu, Zn) standard solutions for ICP analysis (Analytika Praha, Czechia, concentration $1 \mathrm{~g} \mathrm{l}^{-1}$ ). The salts of $\mathrm{NaCl}$ and $\mathrm{KCl}$ were of p.a. purity better than 99 and 99.5\%, respectively (Onex Chemie, Ltd., Roznov pod Radhostem, Czechia), $\mathrm{MgCl}_{2} \cdot 2 \mathrm{H}_{2} \mathrm{O} \geq 99 \%$ (Sigma Aldrich, USA), $\mathrm{CaCl}_{2} \cdot 2 \mathrm{H}_{2} \mathrm{O} \geq$ 99\% (Cambrian Chemicals, Canada), $\mathrm{SrCl}_{2} \cdot 6 \mathrm{H}_{2} \mathrm{O} \geq 99 \%$ and $\mathrm{BaCl}_{2} \cdot 2 \mathrm{H}_{2} \mathrm{O} \geq 99 \%$ (both by Lachema Brno, Czechia) and they were first dried for several hours at more than $110{ }^{\circ} \mathrm{C}$ in a drying oven and then placed in desiccator to remove water. Then, they

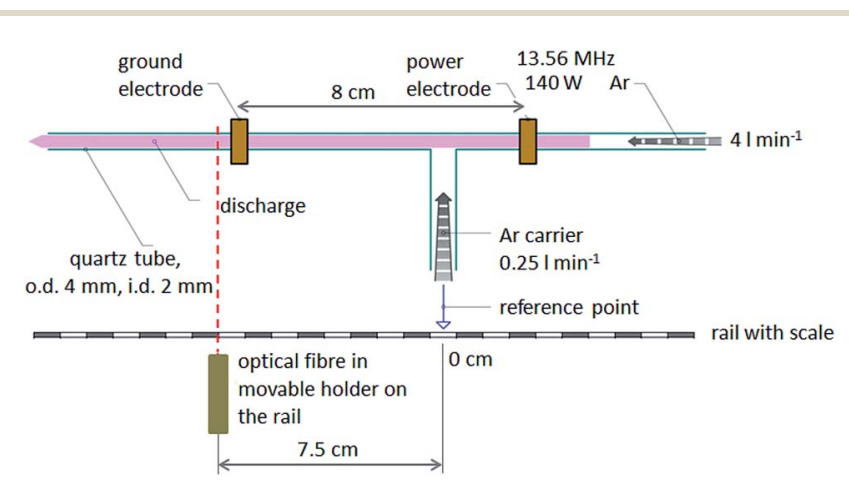

Fig. 1 Experimental scheme of the plasma pencil. 
were weighed using an analytical balance to prepare stock water solutions of $100 \mathrm{~g} \mathrm{l}^{-1}$ concentration for further dilution and mixing with $\mathrm{Zn}$ and $\mathrm{Cu}$ standards. The final solutions were the following mixtures of $\mathrm{Cu}$ or $\mathrm{Zn}$ (in concentration of $20 \mathrm{mg} \mathrm{l}^{-1}$ ) and with one interferent $\left(\mathrm{mg} \mathrm{l}^{-1}\right): 0,50,100,150,200,250,300$, $350,400,600,800,1000,2000$ or 4000 . The chosen $\mathrm{Zn}$ and $\mathrm{Cu}$ compromise concentration ensured sufficient line intensities along the discharge axis for both $\mathrm{Zn}$ and $\mathrm{Cu}$, and would also not saturate the detector in case of $\mathrm{Cu}$ at higher concentrations. Copper and zinc were chosen because their excitation was well monitored in our previous studies, ${ }^{5,6}$ and they are the only elements not belonging to EIE in the element set investigated using our plasma pencil. Their molar mass is also very similar and therefore, the differences in the molar concentrations of their solutions are negligible.

The salt concentration range was chosen based on preliminary tests with up to $40 \mathrm{~g} \mathrm{l}^{-1}$ solutions. The range of $50-1000 \mathrm{mg}$ $\mathrm{I}^{-1}$ is the most interesting interval in terms of the observed changes and the discharge tube was not contaminated with salt sediments during the time of spectra acquisition.

The concentrations of salt solutions were verified by ICP-OES Thermo iCAP 6500 DUO at our laboratory.

\section{Results and discussion}

The investigation of the plasma pencil discharge was lead in four ways. The first measurement was carried out along the discharge tube without and with the presence of the interferents in order to reveal whether the axial intensity profile was changed by the interferent. Optimal position for spectra acquisition was chosen at $7.5 \mathrm{~cm}$ from the sample inlet. ${ }^{5,6}$ In this position, the maximum emission of most atomic lines can be detected. ${ }^{5,6}$ The second measurement compared the net intensities of copper and zinc lines without and with the presence of salts at various concentrations. The third part was focused on the plasma diagnostics. It is important to know if the presence of EIE changes the discharge temperatures and electron number density. Then, the changes can be compared and eventually correlated with the measured changes of line intensities. The fourth part was devoted to the sample introduction system, which can be affected by the dissolved salts. The nebulization efficiency can be decreased and the particle size distribution can be changed. This effect should be subtracted from the effects in the plasma.

Firstly, it should be highlighted that the discharge was very stable under any load of salt. The stability was apparently influenced by the water presence, but not by the dissolved inorganic substance. Some experiments were carried with $\mathrm{NaCl}$ concentrations up to $40 \mathrm{~g} \mathrm{l}^{-1}$, but the high concentrations were abandoned to be unreal and only comparable with non-diluted sea water. Also, in this case, the discharge stability was still superior, but the discharge tube became contaminated by the salt after several minutes. The experiments were further continued in the salt concentration range of 0 to $4 \mathrm{~g} \mathrm{l}^{-1}$. The results show that this was a good choice.

The measured profiles of line intensities along the discharge tube with or without salts follow the same trend as in our previous study where the maximum emission was just behind the ground electrode. ${ }^{6}$ We illustrate the effect of salt in Fig. 2a and $\mathrm{b}$. The effect of $0.4 \mathrm{~g} \mathrm{l}^{-1}$ of $\mathrm{NaCl}$ on $\mathrm{Cu}$ and $\mathrm{Zn}$ emission is depressive in any position, but the shape remains unchanged.

The profiles were normalized to the maximum intensity of the $\mathrm{Cu}$ or $\mathrm{Zn}$ in pure water solution. Error bars in Fig. 2a and $\mathrm{b}$ do not exceed the dimensions of the symbols in the graphs.

The second experiment confirmed the assumption that the measured atomic emission lines of $\mathrm{Cu}$ I $(324.754,327.396$, 510.554 and $578.213 \mathrm{~nm})$ and $\mathrm{Zn} \mathrm{I}(213.857,468.014,472.216$ and $481.053 \mathrm{~nm}$ ) were suppressed by the presence of EIE salts (Fig. 3a-d). The dependences were measured in the optimal position of $7.5 \mathrm{~cm}$ from the sample inlet. The dependences were constructed from two curves measured in a time interval of about one year. Instead of two curves for each EIE, the error bars show positions of two points from two curves for each EIE concentration and the point in the middle is the average of these two points.

The behaviour of all copper lines can be described by one curve, which can be understandable due to very close upper levels. Surprisingly, all measurable zinc lines emitted by the plasma pencil show the identical behaviour described by another common curve. The line intensities steeply decreased
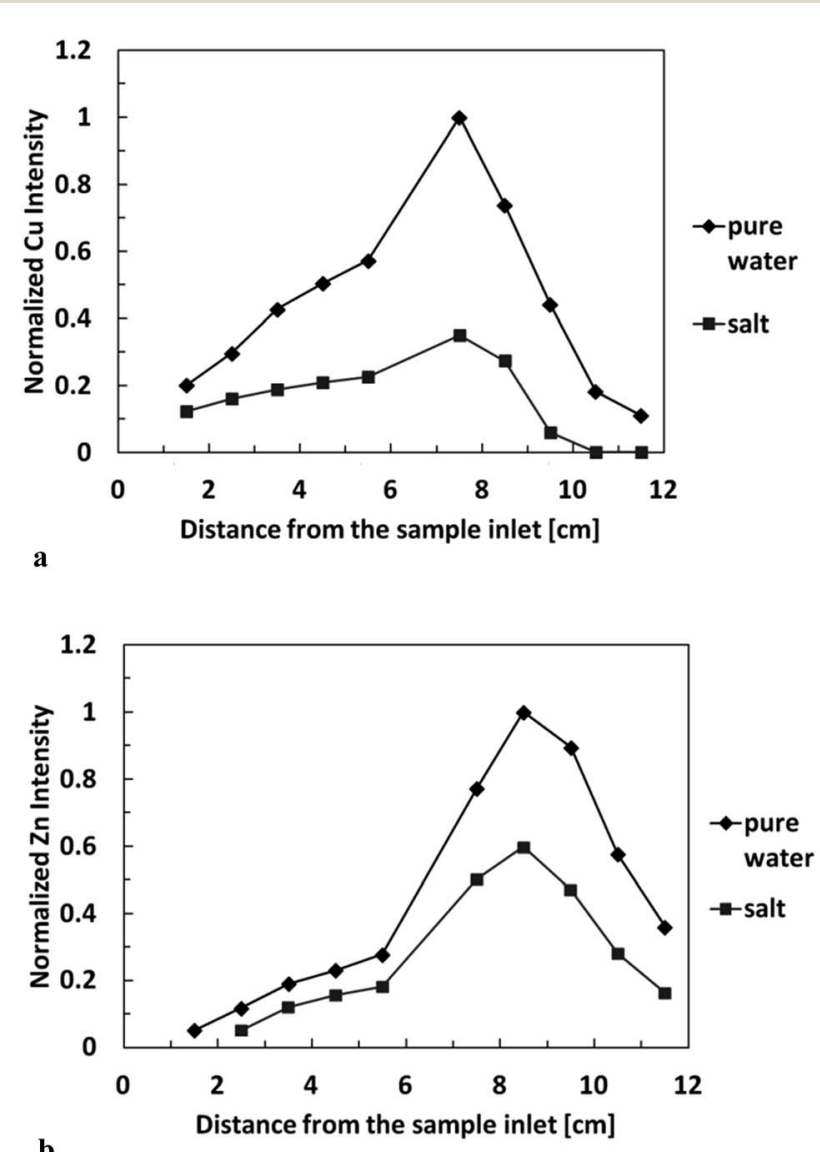

b

Fig. 2 (a) Profile of the Cu I $324.754 \mathrm{~nm}$ emission along the discharge axis with pure water and with $0.4 \mathrm{~g} \mathrm{l}^{-1}$ of $\mathrm{NaCl}$. (b) Profile of the $\mathrm{Zn} \mathrm{I}$ $213.856 \mathrm{~nm}$ emission along the discharge axis with pure water and with $0.4 \mathrm{~g} \mathrm{l}^{-1}$ of $\mathrm{NaCl}$. 

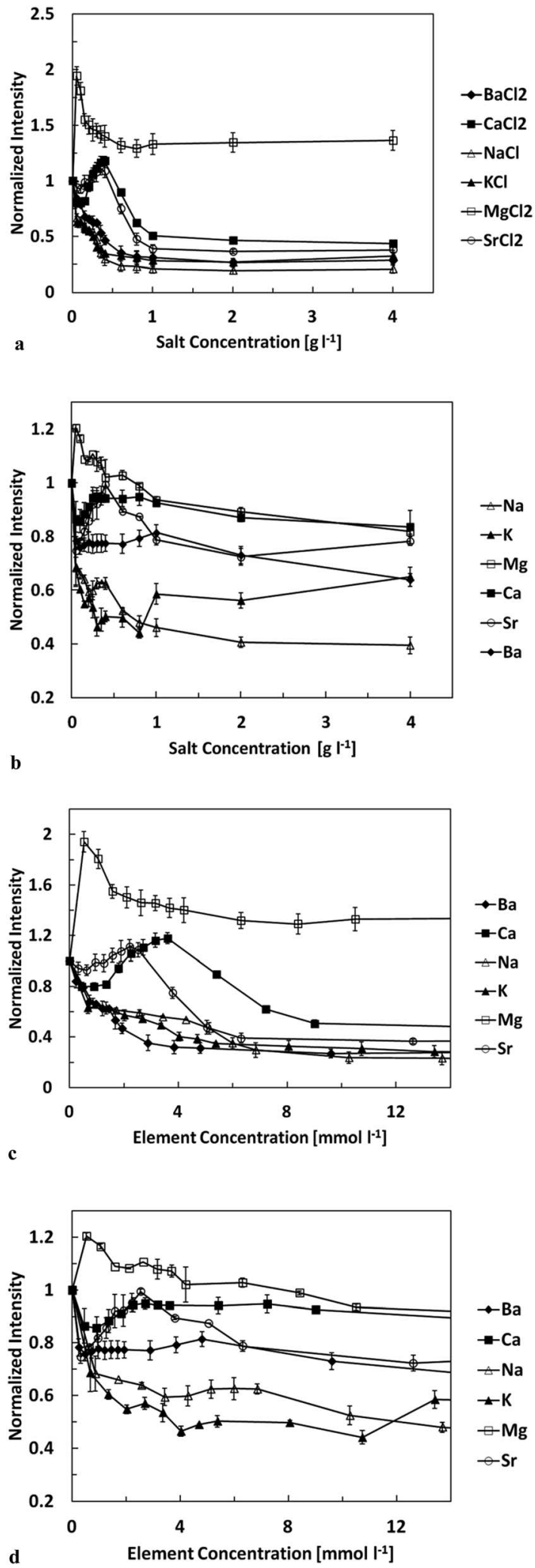

Fig. 3 (a) Normalized emission intensity of $\mathrm{Cu} I$ lines for various concentrations of salts. (b) Normalized emission intensity of $\mathrm{Zn} I$ lines for various concentrations of salts. (c) Normalized emission intensity of $\mathrm{Cu}$ I lines for various molar concentrations of EIE. (d) Normalized emission intensity of $\mathrm{Zn} I$ lines for various molar concentrations of EIE. down until about $0.6-0.8 \mathrm{~g} \mathrm{l}^{-1}$ of $\mathrm{NaCl}, \mathrm{KCl}$ or $\mathrm{BaCl}_{2}$ (Fig. $1 \mathrm{a}$ and b). Higher salt concentrations have only a minor effect. The signals are nearly in a lower plateau. It is supposed that concentrations over $4 \mathrm{~g} \mathrm{l}^{-1}$ do not bring any significant change. Over $1 \mathrm{~g} \mathrm{l}^{-1}$, both $\mathrm{Cu}$ and $\mathrm{Zn}$ line intensities are stable. The zinc lines are less affected than the copper ones and $\mathrm{KCl}$ shows a little bit more of the depressive effect than $\mathrm{NaCl}$ on both $\mathrm{Cu}$ and $\mathrm{Zn}$ emission. Potassium, however, tends to a reverse effect over $1 \mathrm{~g} \mathrm{l}^{-1}$. Sodium is rather prone to the behaviour of other EIE by creating a plateau at lower concentrations (Fig. 3a-d). For higher concentrations, the sodium effect on zinc is more stable and stronger than for potassium.

Better insight to the effects are offered in Fig. $3 c$ and $d$.

As can be seen, the measured dependences in Fig. 3a-d are not monotonous. They show that the effect of the EIE consists of several mechanisms contributing and demonstrating themselves to various extent for various EIE concentrations. Two basic trends are observable. One is increasing and strengthening for lower EIE concentrations with concomitant high EIE ionization energy. The other is depressive, and it prevails for higher EIE concentrations and for EIE with lower ionization energies. The increasing effect is strongest when the ionization energy of the concomitant is relatively high, but still little bit lower than that of copper and zinc. It can then be supposed that relatively low concomitant concentration consumes energy from the plasma for its preferential ionization. The copper and zinc atoms can yield less energy from the plasma than without the concomitant; however, it is still enough for their excitation, but less for their ionization. Therefore, there are more $\mathrm{Cu}$ and $\mathrm{Zn}$ atoms than without the presence of EIE; the atomic lines show higher intensities and the concomitant acts as an ionization buffer. The higher concomitant concentration consumes too much energy from the plasma and the buffer mechanism cannot further compensate the energy loss for copper and zinc. Higher EIE concentrations thus lead to signal suppression of copper and zinc. All the investigated EIE show stronger depression effects than the buffer with the one exception of magnesium. This element has the highest ionization energy and, although the copper and zinc signal intensity decrease is present, for copper the buffer effect wins over the whole measured concentration range. When the concomitant ionization energy is low, the local intensity maximum is less distinct and the shape of the measured dependence is governed mainly by the depression effect. The dependence of the depression effect, $X$, on the concomitant ionization energy is depicted in Fig. 4. There are experimental and model dependences for both copper and zinc atoms. The effect is plotted for low EIE concentrations of 1-3 mmol $\mathrm{l}^{-1}$ when the buffer effect shows a local maximum in Fig. 3a-d.

Although there is no exact theoretical reason, we proposed an empirical formula describing the magnitude of $X$ for the local maximum, which could be attributable to the ionization buffering and was observable at lower EIE concentrations (Fig. 3a-d):

$$
X=1-\left(E_{\mathrm{ul}}-E_{\mathrm{iEIE}}\right) / E_{\mathrm{iEIE}}
$$




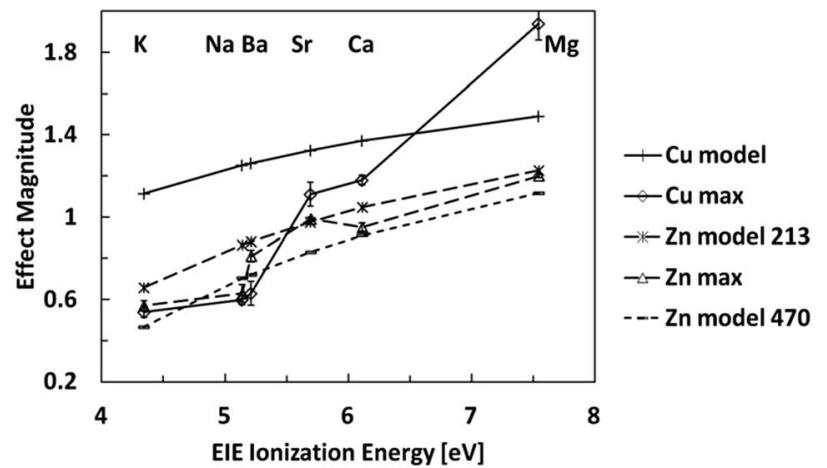

Fig. 4 The magnitude $X$ of the EIE effect corresponding to its local maximum as a function of EIE ionization energy. One model curve for all Cu lines and two model curves for $\mathrm{Zn}$ (upper dashed for $\mathrm{Zn} 1213.856$ $\mathrm{nm}$, lower dashed for the other $Z n$ lines 468.014, 472.216, $481.053 \mathrm{~nm}$ ) and experimental curves for $\mathrm{Cu}$ and $\mathrm{Zn}$ lines are shown.

where $E_{\mathrm{ul}}$ is the upper level of the $\mathrm{Cu}$ or $\mathrm{Zn}$ transition corresponding to the measured line and $E_{\mathrm{iEIE}}$ is ionization energy of the particular EIE.

The experimental zinc curve agrees quite well with the proposed two model curves (Fig. 4). The upper dashed curve describes the model of Zn I $213.856 \mathrm{~nm}(5.82 \mathrm{eV})$ and the lower Zn I 468.014, 472.216 and $481.053 \mathrm{~nm}$ (all upper levels $6.66 \mathrm{eV}$ ). According to the empirical model, these lines should follow the lower model curve. However, one measured curve for all $\mathrm{Zn}$ lines represents the behaviour of all $\mathrm{Zn}$ lines, and this curve is mostly between the theoretical line for $\mathrm{Zn} 213$ and for $\mathrm{Zn}$ $468.014,472.216$ and $481.053 \mathrm{~nm}$. Despite the different excitation energies of the measured zinc lines, they are above or close to the ionization limit of any investigated EIE, in contrast to the copper lines. The experimental copper curve is, however, much more different and shows more extreme behaviour. A partial explanation can be given based on the Grotrian diagram of $\mathrm{Cu}$, $\mathrm{Zn}, \mathrm{Na}, \mathrm{K}, \mathrm{Ba}$ and $\mathrm{Ca}$ constructed from NIST levels. ${ }^{27}$ The measured copper transitions $(324.754,327.396,510.554$ and $578.213 \mathrm{~nm}$ ) have an upper energy level around $30500 \mathrm{~cm}^{-1}$ $(3.8 \mathrm{eV})$ which corresponds to several levels of $\mathrm{Na}, \mathrm{K}$ and $\mathrm{Ba}$. Once more, the zinc upper levels of the transitions are above the ionization limit of any proven EIE, except calcium and magnesium. This fact leads us to suppose that there is likely a resonance energy transfer from the copper to the $\mathrm{Na}, \mathrm{K}$ and $\mathrm{Ba}$ atoms and, to a lesser extent, to $\mathrm{Sr}$ and $\mathrm{Ca}$ atoms. Magnesium levels are very distant from those of copper, and the energy transfer between the levels is improbable. The most abundant element in the plasma is argon, but levels of its excited states are very high. Inelastic collisions leading to the direct resonance energy transfer between argon and zinc, copper or EIE upper levels, of the measured lines, are not supposed.

We realize that the described mechanisms are only a part of the complex system of reactions including also dissociation of water, salts and the forming and collisions of radicals and anions, and the plasma is strongly non-isothermic (excitation temperature from $\mathrm{Ar}$ atomic lines around $3000 \mathrm{~K}$ and temperature of neutral gas from rotational lines of $\mathrm{OH}$ around $1000 \mathrm{~K}$ ). However, we suppose that the experimental results sufficiently fit the three major proposed atomic mechanisms of ionization buffering, energy loss by preferential EIE ionization and resonance energy loss in the case of copper. Taking into account the results of previous studies of CCP with electrothermal vaporization (mainly supplement 4$)^{26}$ we suppose that the observed phenomena originate just in the plasma, not in the introduction system.

The presence of EIE also poses a question of if the discharge is influenced by their abundant ionization. Increased ionization could potentially change the electron number density and temperatures, shift the ionization equilibrium and change the degree of ionization of the introduced elements. ${ }^{28}$ In case of this study, the same sets of $\mathrm{OH}$ rotational lines $\left(\mathrm{Q}_{1} 1-\mathrm{Q}_{1} 9\right)$ to calculate gas temperature $T_{\mathrm{g}}$, $\mathrm{Ar} I$ lines (603.21, 667.73, 675.28, 687.13 and $714.70 \mathrm{~nm}$ ) to calculate excitation temperature $T_{\mathrm{e}}$ from the slope of the Boltzmann plot and $\mathrm{H}_{\beta}$ line were used as in our previous works. ${ }^{5,6}$ The results show that these parameters do not change for the measured salt concentration range of 0 to $4 \mathrm{~g}$ $1^{-1}$. The presentation of that plot, is thus, superfluous. These results are consistent with our previous study. ${ }^{5}$ The observed changes of $T_{\mathrm{g}}(970-1030 \mathrm{~K}), T_{\mathrm{e}}(2850-2890 \mathrm{~K})$ and $N_{\mathrm{e}}(4.5-4.7 \times$ $10^{19} \mathrm{~m}^{-3}$ ) in dependence on the salt concentration do not show any trend and are statistically unimportant. This result agrees with our former observations that changes of $T_{\mathrm{g}}, T_{\mathrm{e}}$ and $N_{\mathrm{e}}$ of this discharge are rather sensitive to the mode of operation (pulsed or continuous) $^{6}$ and lateral position of observation ${ }^{5}$ (from the sample inlet), but insensitive to the diluted salts. ${ }^{5}$ The present energy in the discharge remains unchanged but is redistributed according to the energy demand of the present species. Moreover, the introduced element concentrations in the plasma were still several orders of magnitude lower than the argon concentration.

Many years ago the role of the sample introduction system was investigated on the measured intensities. The double pass Scott spray chamber (used in our experiments) was reported to be a source of the signal lowering due to several effects of aerosol redistribution when containing salts. ${ }^{8}$ In our experiment, no nebulisation efficiency change was measured by the method of weighing the sample and the waste bottles after a defined time $e^{5}$ of nebulisation for the salt concentrations: 0 , $0.2,0.4,0.8$ and $2.0 \mathrm{~g} \mathrm{l}^{-1}$. Although the aerosol particle size distribution of the smallest droplets and their evaporation in the plasma can be changed the method of weighing is incapable to discover these mechanisms in our study. Nevertheless, we do not suppose substantial distortion of our results by the nebulisation effects due to still relatively low salts concentrations.

\section{Conclusions}

In the present study, we proved a substantial depression effect of the easily ionisable elements $\mathrm{Na}, \mathrm{K}$ and $\mathrm{Ba}$, strongly increasing effect of $\mathrm{Mg}$ and, to some extent, $\mathrm{Ca}$ and $\mathrm{Sr}$ on the intensities of the atomic emission lines $\mathrm{Cu}$ I 324.754, 327.396, 510.554, 578.213 and Zn I 213.899, 468.014, 472.216, 481.053 $\mathrm{nm}$ isolated from the spectrum of the plasma pencil. The effect is stronger for the $\mathrm{Cu}$ lines than for the $\mathrm{Zn}$ lines. All the $\mathrm{Cu}$ lines showed the same behaviour and the group of $\mathrm{Zn}$ lines can also 
be described by a single trend, although the Zn I $213.856 \mathrm{~nm}$ line has a lower upper energy level than the remaining three $\mathrm{Zn}$ lines. The effect is relatively strongest for lower EIE concentrations, up to about $0.6-0.8 \mathrm{~g} \mathrm{l}^{-1}$; while at over about $1 \mathrm{~g} \mathrm{l}^{-1}$ of the salt, it is relatively weaker or nearly saturated at a constant value, and even slightly positive such that a weak increase of the intensity is observed. Based on the early published results, this behaviour can be explained by the surplus of low energy free electrons from ionization of $\mathrm{Na}$ and $\mathrm{K}$, shift of the ionisation equilibrium to the atoms and close energy levels of $\mathrm{Cu}$ to those of mainly $\mathrm{Na}$ and $\mathrm{K}$, leading to the loss of $\mathrm{Cu}$ energy, likely through resonant inelastic collisions with the $\mathrm{Na}$ and $\mathrm{K}$ atoms. The effect of EIE lower concentrations on $\mathrm{Zn}$ can be efficiently described by a simple empirical formula. The weaker effect on $\mathrm{Zn}$ is attributable to the upper energy level of the measured $\mathrm{Zn}$ transition evenly over most EIE ionization limits. The $\mathrm{Cu}$ and $\mathrm{Zn}$ intensity distribution in the presence of EIE along the discharge axis follows the distribution of the $\mathrm{Cu}$ and $\mathrm{Zn}$ emission in the presence of pure water.

No significant changes in excitation and neutral gas temperature, nor electron number density, were found in the concentration range of 0 to $4 \mathrm{~g} \mathrm{l}^{-1}$ of salts. This can indicate that the main source of the $\mathrm{Cu}$ and $\mathrm{Zn}$ signal depression is a comprehensive set of inelastic collisional reactions and energy redistribution in the plasma and not general plasma cooling by an enhanced amount of the salts.

\section{Acknowledgements}

This research was carried out under the project CEITEC 2020 (LQ1601) with financial support from the Ministry of Education, Youth and Sports of the Czech Republic under the National Sustainability Programme II. This research has been also supported by the project CZ.1.05/2.1.00/03.0086 funded by European Regional Development Fund and project LO1411 (NPU I) funded by Ministry of Education, Youth and Sports of Czech Republic.

\section{Notes and references}

1 M. Klíma, J. Janča, V. Kapička, P. Slavíček and P. Saul, Czech patent No. 286310 (prior.12.5.1998) or PCT/CZ99/00012, 1998.

2 J. Janča, M. Klíma, P. Slavíček and L. Zajíčková, Surf. Coat. Technol., 1999, 116-119, 547-551.

3 M. Šíra, M. Klíma, J. Janča, V. Kapička and M. Čapoun, Czech. J. Phys., 2000, 50(S3), 415-418.

4 P. Slavíček, V. Buršíková, A. Brablec, V. Kapička and M. Klíma, Czech. J. Phys., 2004, 54, 586-591.
5 L. Novosád, A. Hrdlička, P. Slavíček, V. Otruba and V. Kanický, J. Anal. At. Spectrom., 2012, 27, 305-309.

6 L. Novosád, A. Hrdlička, P. Slavíček, V. Otruba and V. Kanický, J. Anal. At. Spectrom., 2015, 30, 459-467.

7 Inductively coupled plasmas in analytical atomic spectrometry, ed. A. Montaser and D. W. Golightly, Wiley, 2nd edn, 1992.

8 J.-M. Mermet, J. Anal. At. Spectrom., 1998, 13, 419-422.

9 M. Villaneuva, M. Catasús, E. D. Salin and M. Pomares, J. Anal. At. Spectrom., 2000, 15, 877-881.

10 C. Dubuisson, E. Poussel and J.-M. Mermet, J. Anal. At. Spectrom., 1998, 13, 1265-1269.

11 P. Masson, Spectrochim. Acta, Part B, 1999, 54, 603-612.

12 E. G. C.-Y. Chan, W.-T. Chan, X. Mao and R. E. Russo, Spectrochim. Acta, Part B, 2001, 56, 1375-1386.

13 M. Grotti, C. Ianni and R. Frache, Talanta, 2002, 57, 10531066.

14 J. L. Todolí, L. Gras, V. Hernandis and J. Mora, J. Anal. At. Spectrom., 2002, 17, 142-169.

15 I. Kroslakova and D. Günther, J. Anal. At. Spectrom., 2007, 22, 51-61.

16 K. Newmann and R. B. Georg, Chem. Geol., 2012, 304-305, 151-157.

17 M. Ponta, M. Frentiu and T. Frentiu, Acta Chim. Slov., 2012, 59, 359-365.

18 M. M. Rahman and M. W. Blades, Spectrochim. Acta, Part B, 2000, 55, 327-338.

19 E. A. Cordos, S. D. Anghel and T. Frentiu, J. Anal. At. Spectrom., 1994, 9, 635-641.

20 T. Frentiu, M. Ponta, E. Darvasi, M. Frentiu and E. A. Cordos, Acta Chim. Slov., 2010, 57, 173-181.

21 T. Frentiu, D. Petreus, M. Senila, A. I. Mihaltan, E. Darvasi, M. Ponta, E. Plaian and E. A. Cordos, Microchem. J., 2011, 97, 188-195.

22 Z. Zhang and K. Wagatsuma, Spectrochim. Acta, Part B, 2002, 57, 1247-1257.

23 K. Jankowski and M. Dreger, J. Anal. At. Spectrom., 2000, 15, 269-276.

24 J. L. Venzie and R. K. Marcus, Spectrochim. Acta, Part B, 2006, 61, 715-721.

25 T. Frentiu, M. Ponta, E. Darvasi, M. Ferntiu and E. Cordos, Food Chem., 2012, 134, 2447.

26 T. Frentiu, E. Darvasi, S. Butaciu, M. Ponta, D. Petreus, A. I. Mihaltan and M. Frentiu, Talanta, 2014, 129, 72-78.

27 http://physics.nist.gov/PhysRefData/ASD/levels_form.html.

28 R. E. Sturgeon and R. Guevremont, J. Anal. At. Spectrom., 1998, 13, 229-233. 